\title{
Carburizer Effect on Cast Iron Solidification
}

\author{
Krzysztof Janerka, Marcin Kondracki, Jan Jezierski, Jan Szajnar, and Marcin Stawarz
}

(Submitted October 31, 2013; in revised form March 18, 2014; published online April 23, 2014)

\begin{abstract}
This paper presents the effect of carburizing materials on cast iron solidification and crystallization. The studies consisted of cast iron preparation from steel scrap and different carburizers. For a comparison, pig iron was exclusively used in a solid charge. Crystallization analysis revealed the influence of the carburizer material on the crystallization curves as well as differences in the solidification paths of cast iron prepared with the use of different charge materials. The carburizers' influence on undercooling during the eutectic crystallization process was analyzed. The lowest undercooling rate was recorded for the melt with pig iron, then for synthetic graphite, natural graphite, anthracite, and petroleum coke (the highest undercooling rate). So a hypothesis was formulated that eutectic cells are created most effectively with the presence of carbon from pig iron (the highest nucleation potential), and then for the graphite materials (crystallographic similarity with the carbon precipitation in the cast iron). The most difficult eutectic crystallization is for anthracite and petroleum coke (higher undercooling is necessary). This knowledge can be crucial when the foundry plant is going to change the solid charge composition replacing the pig iron by steel scrap and the recarburization process.
\end{abstract}

Keywords casting, crystallization, microstructure, phase diagram, solidification, thermal analysis

\section{Introduction}

The technological process of alloy production can be carried out with the use of different types of melting furnaces and with the use of different charge materials, e.g. cast iron can be produced in a cupola furnace or an electrical furnace with or without the use of pig iron ( $\operatorname{Ref} 1,2)$. It is assumed that the application of different charge materials leads to inheritance of their structure and properties in the resulting alloy. For cast iron, that inheritance is connected with the transfer of pig iron (Ref 1,2$)$ or steel scrap and carburizer (Ref 3, 4) properties. In studies, authors have observed that there are differences in the cooling and crystallization curves along with the use of different charge materials with an assumed similar chemical composition of the resulting alloy (Ref 5). This indicates that the TDA curves registered during cast iron solidification can be treated as a kind of "passport" of the given alloy. Furthermore, the re-melting of cast iron does not eliminate the differences in the TDA curves, i.e., they remain the same. There is a need to explain the situation as presented above and to elaborate on the possible application of so far collected knowledge, which is important from a scientific and practical point of view. Increasingly, cast iron production is utilizing only steel scrap charge materials and different carburizers, thus excluding pig iron application (Ref 6-8).

Krzysztof Janerka, Marcin Kondracki, Jan Jezierski, Jan Szajnar, and Marcin Stawarz, Department of Foundry Engineering, Faculty of Mechanical Engineering, Silesian University of Technology, Towarowa 7, 44-100 Gliwice, Poland. Contact e-mail: jan.jezierski@polsl.pl.

\section{Methodology of Studies}

The studies consisted of cast iron EN GJL 250 and EN GJL 300 preparation from steel scrap and different carburizers (natural graphite - GN, synthetic graphite - GS, anthracite-A, petroleum coke- KN) and, for comparison, with the use of special pig iron (denoted by $\mathrm{S}$ ). Chemical analysis of the carburizers is presented in Table 1. They were introduced into melting furnace with solid charge in portion from 360 to $440 \mathrm{~g}$ depends on planned carbon content from initial $0.21 \%$ (resulted from scrap metal grade being used). Steel scrap with following chemistry: $0.21 \% \mathrm{C}, 0.18 \% \mathrm{Si}, 0.48 \% \mathrm{Mn}, 0.026 \mathrm{P}, 0.015 \% \mathrm{~S}$, and 100 ppm of nitrogen was used during the melts. A special pig iron was used and its chemistry was as follows: $4.50 \% \mathrm{C}$, $0.68 \% \mathrm{Si}, 0.038 \mathrm{Mn}, 0.050 \% \mathrm{P}, 0.018 \% \mathrm{~S}$, and $43 \mathrm{ppm}$ of nitrogen. Carburizers were introduced together with the scrap steel in a calculated quantity. Experimental melts using metallurgical grade silicon carbide ( $\mathrm{SiC}$ ) with a $\mathrm{Si}$ content of $88 \%, 1.40 \%$ $\mathrm{Si}+\mathrm{SiO}_{2}, \max 0.8 \% \mathrm{Fe}_{2} \mathrm{O}_{3}, \max 0.3 \% \mathrm{C}$ were additionally carried out. This material was used to improve the nucleation potential of the liquid alloy. However, because introducing the $\mathrm{SiC}$ portion with steel scrap causes a carbon content increase of $1.30 \%$ and at the same time a Si content increase of $2.80 \%$, it was necessary to compensate the carbon content with the addition of graphite. That is why during the melt marked $\mathrm{SiC}+\mathrm{GS} 2,380 \mathrm{~g}$ of $\mathrm{SiC}$ and $175 \mathrm{~g}$ of GS2 carburizer were introduced. The melts were conducted in an electrical, highfrequency induction furnace with a capacity of $20 \mathrm{~kg}$.

The chemical composition was analyzed for every melt. Crystallization analysis was performed using the thermal and derivative analysis method (TDA). The obtained results of the chemical compositions are shown in Table 2. The first column presents a denotation of the carburizer type.

The carbon content varies in the range of $3.19-3.55 \%$ and the silicon in the range of $1.98-2.16 \%$. Cast iron prepared with the use of pig iron is characterized by a lower content of $\mathrm{Cr}, \mathrm{Ni}$, and $\mathrm{Cu}$. For all the prepared alloys, the eutectic saturation 
Table 1 Chemical composition of carburizers

\begin{tabular}{lllcrrrr}
\hline Carburizer & $\mathbf{C}, \boldsymbol{\%}$ & $\mathbf{S}, \boldsymbol{\%}$ & Volatile parts, $\%$ & Ash, $\%$ & Humidity, \% & N, \% & H, $\%$ \\
\hline GN1 natural graphite & 85.00 & 0.08 & 3.00 & 11.00 & 2.00 & 0.10 & 0.41 \\
A1 anthracite & 92.0 & 0.3 & 2.00 & 8.00 & 1.00 & 0.53 \\
GS1 synthetic graphite & 99.00 & 0.03 & 0.20 & 0.80 & 0.5 & 0.0 \\
GS2 synthetic graphite & 99.35 & 0.015 & 0.08 & 0.57 & 0.09 & 0.32 \\
KN1 petroleum coke & 98.00 & 0.50 & 0.70 & 0.65 & 0.50 & 0.30 \\
KN2 petroleum coke & 98.00 & 0.6 & 1.00 & 0.60 & 0.50 & 0.46 \\
\hline
\end{tabular}

Table 2 Chemical composition of the studied cast iron, in wt.\%

\begin{tabular}{|c|c|c|c|c|c|c|c|c|c|}
\hline & $\mathrm{C}, \%$ & $\mathrm{Si}, \%$ & Mn, \% & P, \% & $\mathrm{S}, \%$ & $\mathrm{Cr}, \%$ & $\mathrm{Ni}, \%$ & Мо, \% & $\mathrm{Cu}, \%$ \\
\hline A1 & 3.55 & 2.12 & 0.16 & 0.024 & 0.0195 & 0.191 & 0.106 & 0.014 & 0.317 \\
\hline GN1 & 3.21 & 2.16 & 0.38 & 0.026 & 0.0280 & 0.127 & 0.092 & 0.024 & 0.278 \\
\hline GS1 & 3.51 & 2.09 & 0.23 & 0.021 & 0.0172 & 0.364 & 0.118 & 0.025 & 0.303 \\
\hline GS2 & 3.30 & 1.96 & 0.46 & 0.033 & 0.0240 & 0.132 & 0.093 & 0.021 & 0.284 \\
\hline KN1 & 3.25 & 2.12 & 0.41 & 0.026 & 0.0288 & 0.075 & 0.094 & 0.015 & 0.271 \\
\hline KN2 & 3.19 & 2.10 & 0.49 & 0.022 & 0.0200 & 0.120 & 0.073 & 0.017 & 0.273 \\
\hline $\mathrm{SiC}+\mathrm{GS} 2$ & 3.25 & 2.00 & 0.64 & 0.019 & 0.0140 & 0.050 & 0.037 & 0.003 & 0.058 \\
\hline $\mathrm{S} 1$ & 3.30 & 1.99 & 0.38 & 0.052 & 0.0208 & 0.033 & 0.023 & 0.013 & 0.125 \\
\hline $\mathrm{S} 2$ & 3.34 & 1.98 & 0.33 & 0.045 & 0.0350 & 0.033 & 0.022 & 0.013 & 0.085 \\
\hline
\end{tabular}

coefficient was lower than 1 , which suggests that the alloys crystalized as hypoeutectic cast iron.

The most popular method of testing alloy crystallization and the alloy properties is via thermal and derivative analysis. This type of measurement is simple, and its results allow to predict some alloy properties in the solid state. Another advantage of the method is the short time of data acquisition (Ref 9-11). During the measurements, the cooling curve is registered and the crystallization curve is calculated on its basis. Generally, it can be said that all changes on the cooling curve are connected with the heat sources occurring during the crystallization. This is a consequence of the constant heat give-up process from a portion of the liquid (solidifying) metal located inside the TDA cup. All the thermal effects registered on the cooling curve are connected with metal crystallization. The lowest value of temperature observed before its following increase is called the undercooling temperature. The first derivative of the cooling curve $(T=f(t))$, shown in a function of time $\left(T^{\prime}=d T / d t(t)\right)$, significantly increases the data set describing the crystallizing alloy, especially in the range of crystallization kinetics (Fig. 1).

Data collected during the TDA analysis can be employed for a precise description of the alloy quality and for property control. The liquidus temperature (denoted as TA) of cast iron is registered in the maximum of the thermal effect connected with primary austenite crystallization, denoted as A on the crystallization curve. Point B can be interpreted as the end of austenite crystallization. The solidus temperature $T_{\mathrm{SM}}$, according to the metastable $\mathrm{Fe}$ $\mathrm{Fe}_{3} \mathrm{C}$ system, can be found in maximum eutectic undercooling and is shown as point $\mathrm{D}$. The stable (Fe-graphite) system $T_{\mathrm{S}}$ temperature can be found on the crystallization curve in point $\mathrm{F}$, where an increase of the temperature after the eutectic undercooling reaches its maximum. The highest rate of metal heating (recalescence) resulting from crystallization heat is denoted by point $\mathrm{E}$. Point $\mathrm{H}$ in the crystallization curve can be interpreted as the end of alloy primary crystallization (solidification), where the last drop of liquid metal transforms into a solid. Temperature $\mathrm{TZ}$ is connected with the pouring temperature (Ref 12). The thermal effect on the crystallization curve can be characterized by sets of

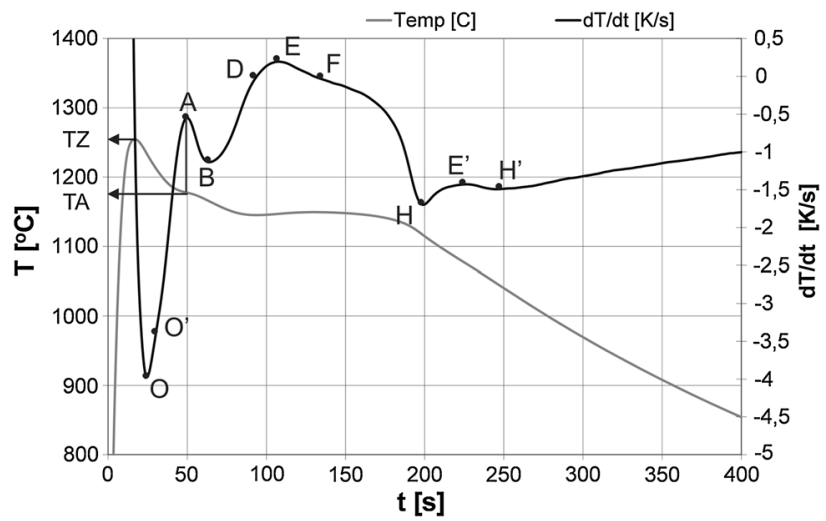

Fig. 1 TDA curves for cast iron together with characteristic points indicated on the crystallization curve

points: $\mathrm{O}^{\prime} \mathrm{AB}$ - crystallization of primary austenite, $\mathrm{BDEFH}$ - crystallization of austenite + graphite eutectic. Some authors describe the thermal effect $\mathrm{HE}^{\prime} \mathrm{H}^{\prime}$ as the crystallization of different carbides $(\mathrm{Fe}, \mathrm{Mn}, \mathrm{Cr}, \mathrm{Mo})_{3} \mathrm{C}$, which occurs due to saturation of the remaining liquid with $\mathrm{Mn}, \mathrm{Cr}$ and $\mathrm{Mo}$ (Ref 13). Nevertheless, the authors found that such effects occur only in the case of cast iron prepared with the use of scrap steel and carburizers, and they originate from another cause, as is explained below. The TDA curves in the function of time for the studied cast irons are shown in Fig. 2-10. The metallographic images of each cast iron are presented on the right.

Analysis of the temperature values in characteristic points of the TDA curves (Fig. 2-10) shows that the range of liquidus temperature for the studied cast irons is $\mathrm{TL}=1177-1236{ }^{\circ} \mathrm{C}$, and for solidus temperature $\mathrm{TS}=1141-1157{ }^{\circ} \mathrm{C}$. Nucleation starts in a similar temperature and the end of primary crystallization, neglecting the type of carburizer, is registered in the range of $1074-1123{ }^{\circ} \mathrm{C}$.

Eutectic crystallization runs in different ways depending on the heat transfer kinetics. For synthetic cast iron produced with the use of carburizers, i.e., natural graphite and synthetic 

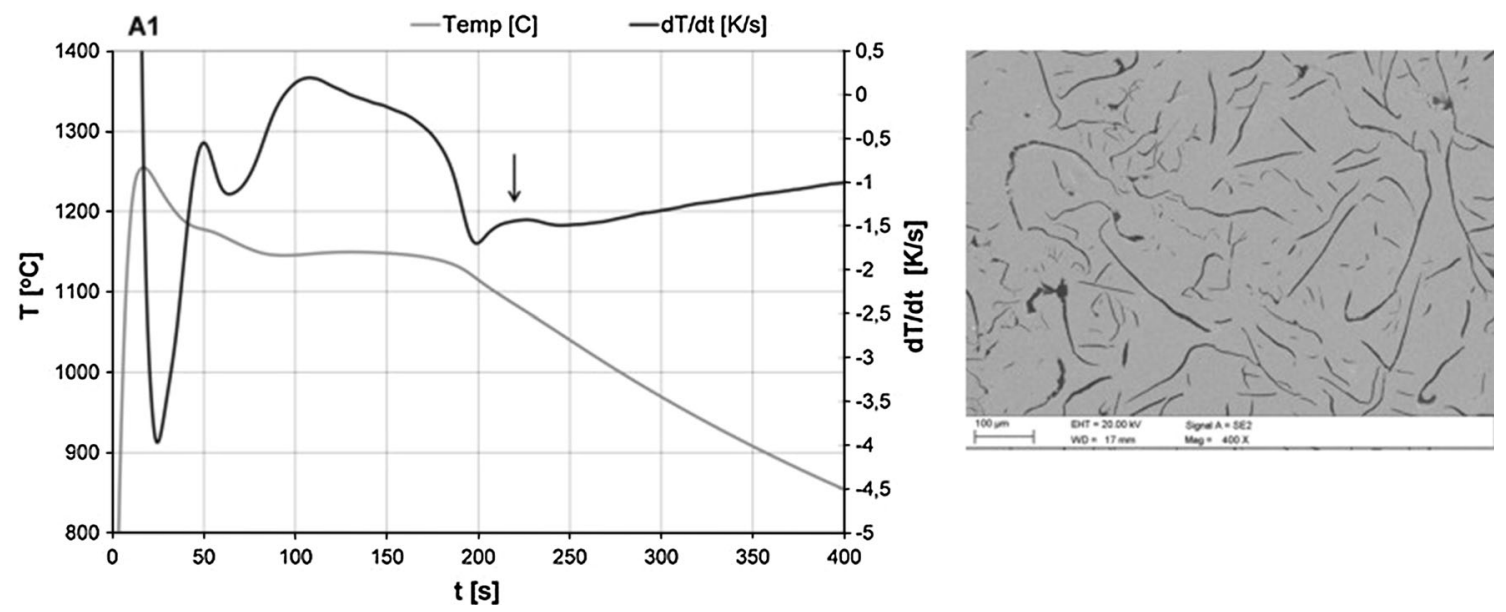

Fig. 2 TDA curves for cast iron prepared with the use of scrap steel and anthracite
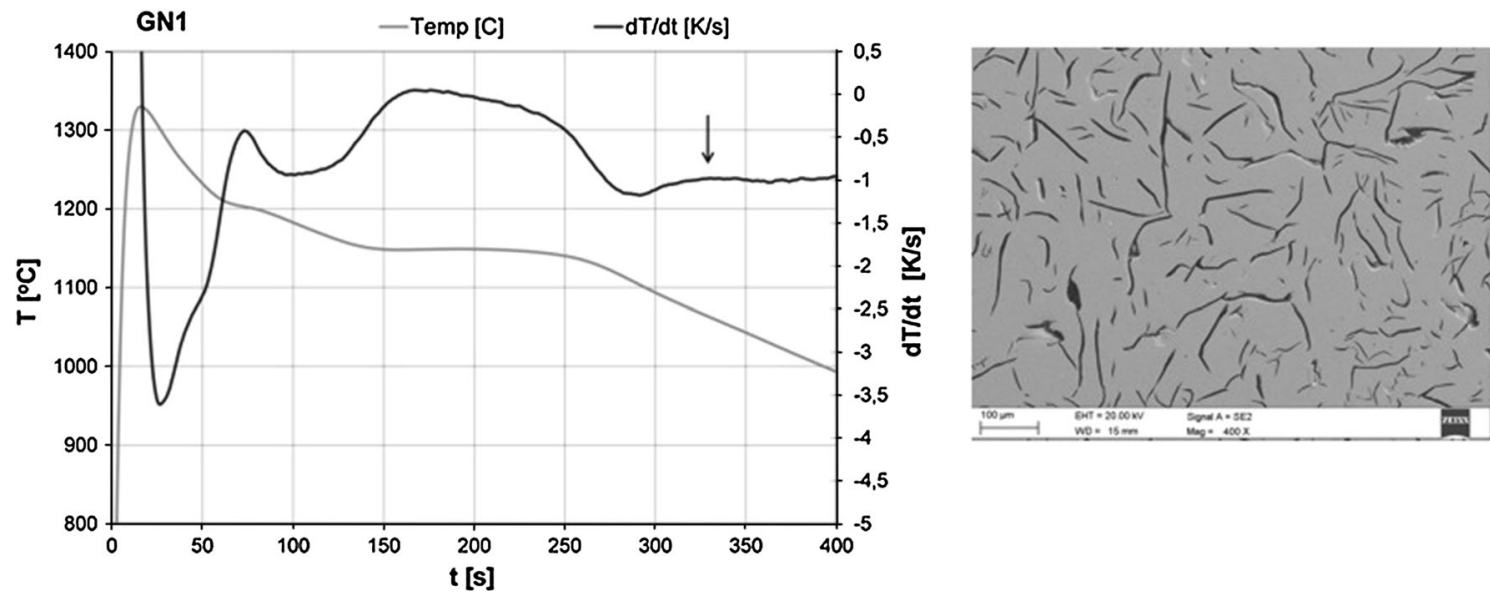

Fig. 3 TDA curves for cast iron prepared with the use of scrap steel and natural graphite GN1
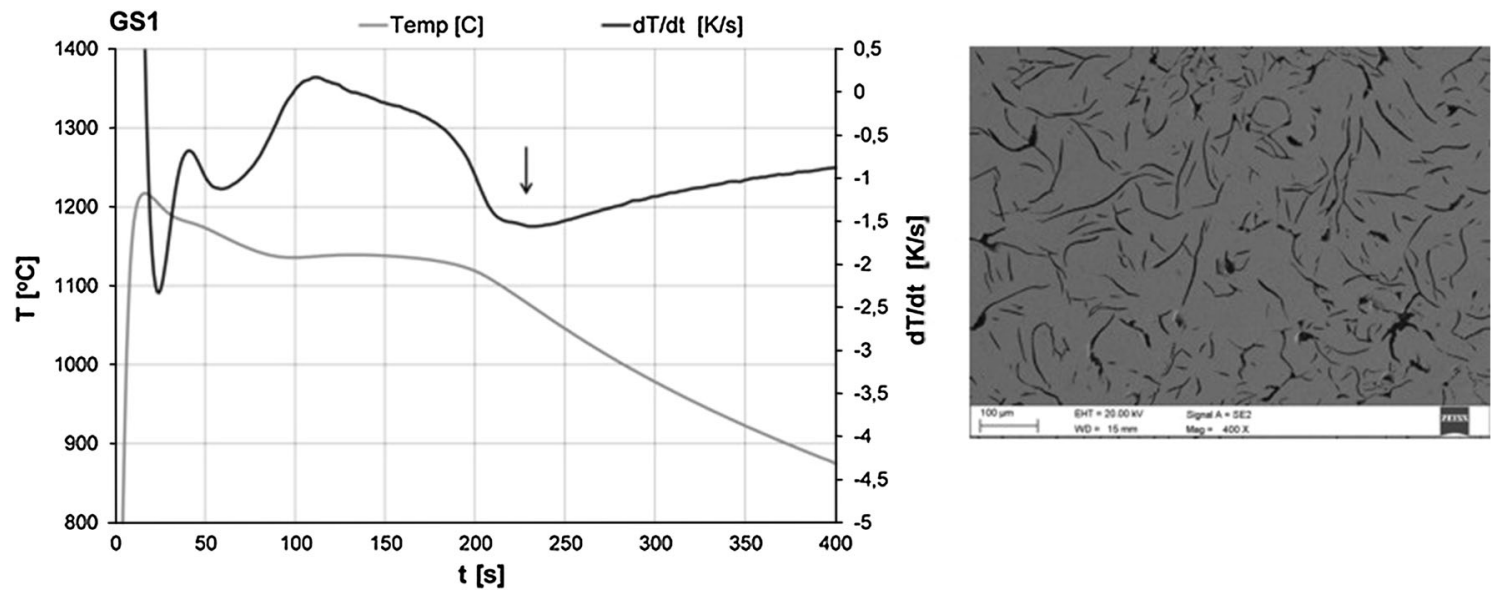

Fig. 4 TDA curves for cast iron prepared with the use of scrap steel and synthetic graphite GS1

graphite, the thermal crystallization effect possesses similar characteristic parameters read from the DTA curves as those recorded for pig iron (GN1, GS2, S1, S2 melts). The eutectic crystallization time is in a range from 160 to $194 \mathrm{~s}$. However, for the rest of the alloys the crystallization curve in the eutectic transformation range is different; eutectic crystallization takes 

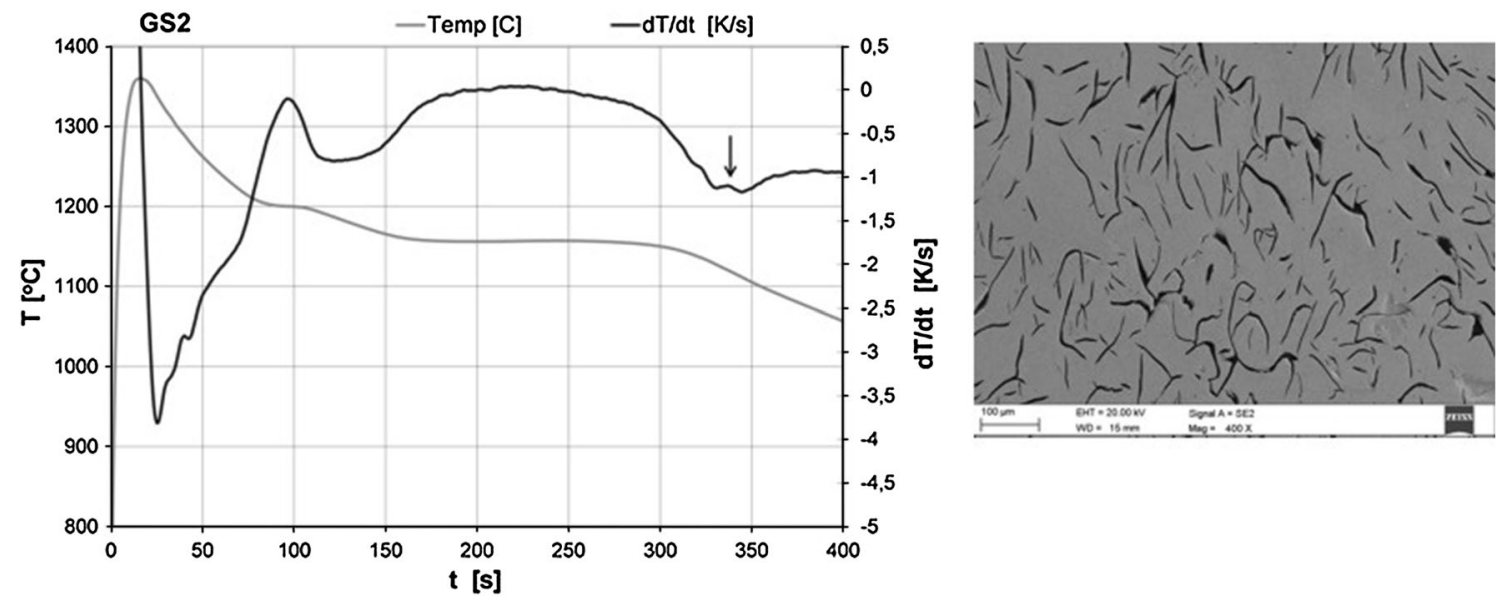

Fig. 5 TDA curves for cast iron prepared with the use of scrap steel and synthetic graphite GS2
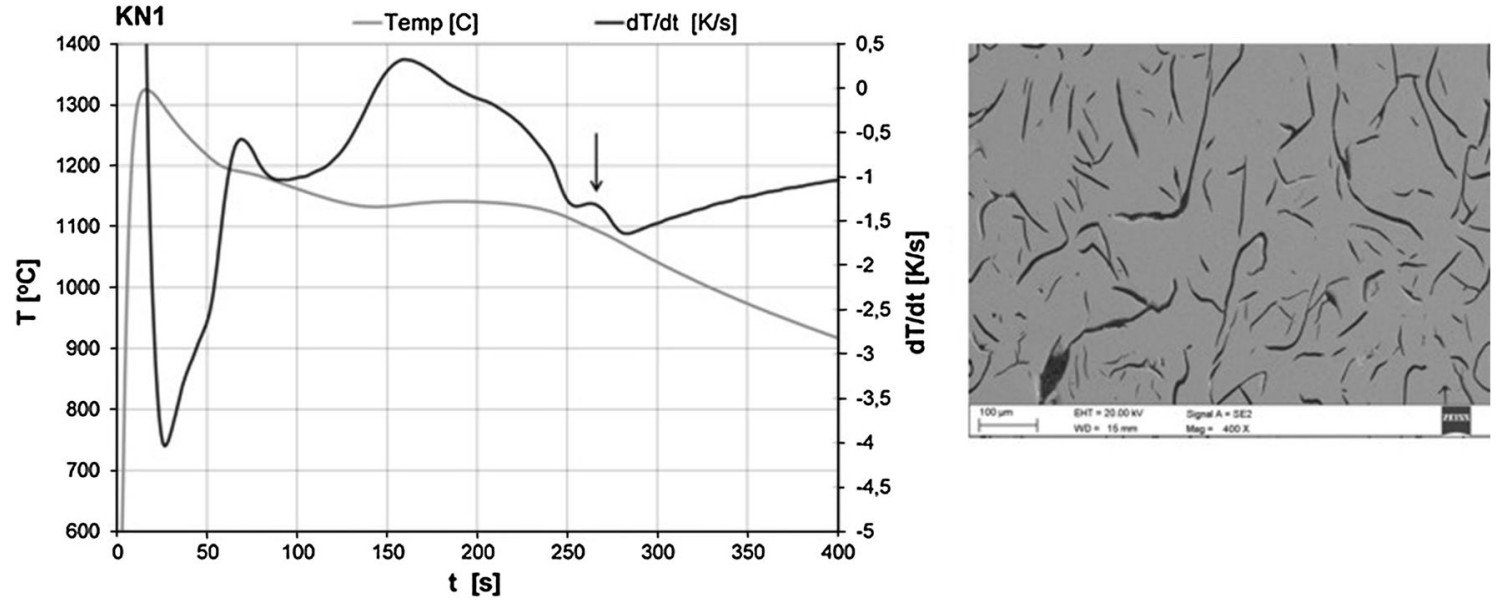

Fig. 6 TDA curves for cast iron prepared with the use of scrap steel and petroleum coke KN1
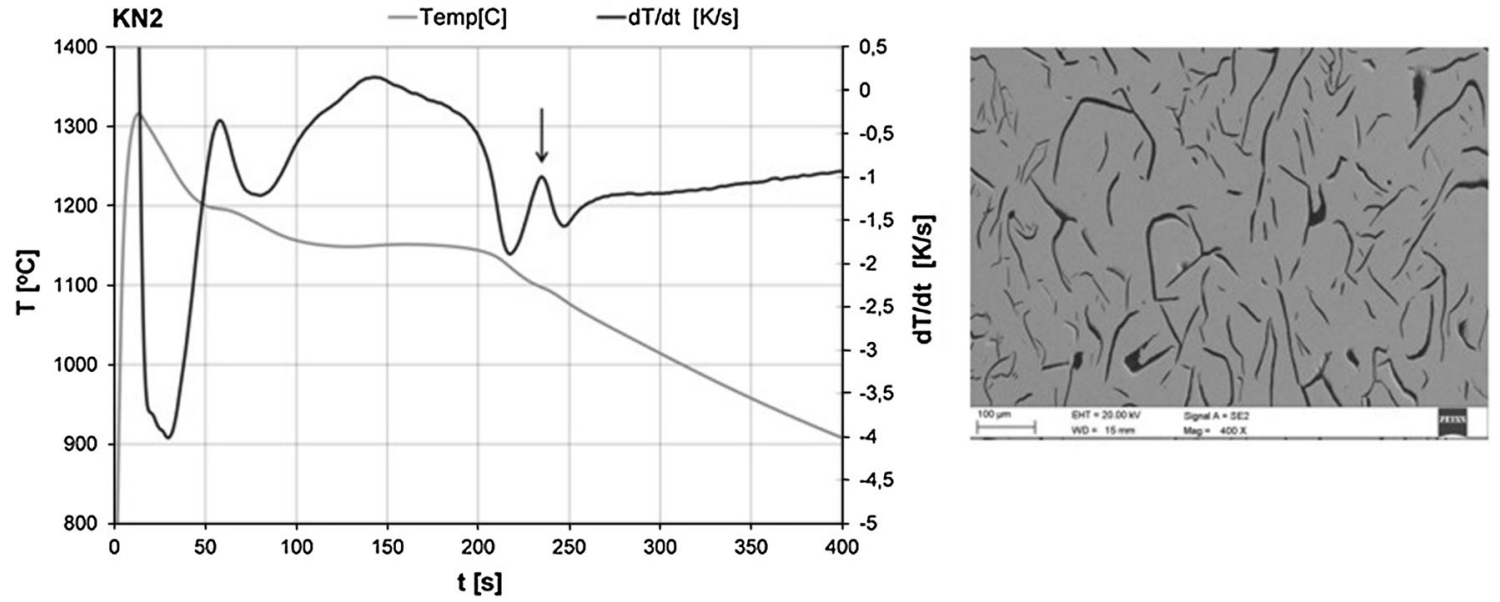

Fig. 7 TDA curves for cast iron prepared with the use of scrap steel and petroleum coke KN2

place in a shorter time period (128-138 s) and the point of the maximum thermal effect from the eutectic crystallization is distinct. The shortest time of eutectic crystallization was recorded for cast iron carburized with $\mathrm{SiC}(128 \mathrm{~s})$, and the longest for synthetic graphite (190 s) and pig iron (194 s). Transformations during primary crystallization of synthetic cast 

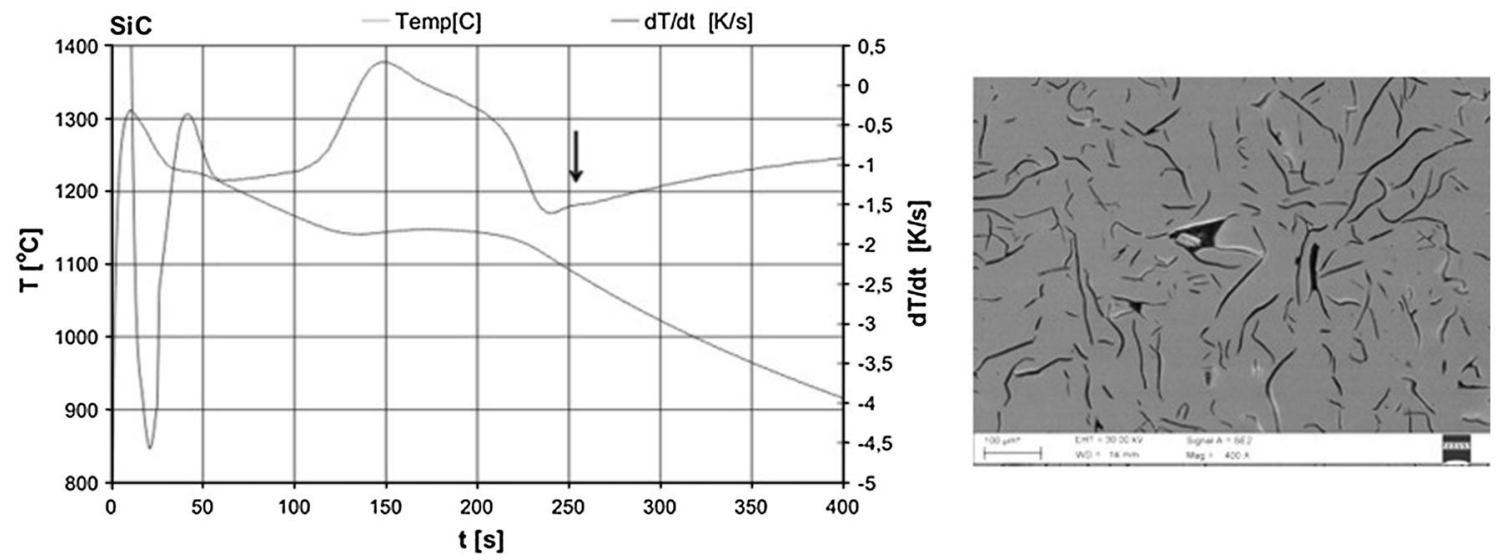

Fig. 8 TDA curves for cast iron prepared with the use of scrap steel, SiC and GS2 carburizers
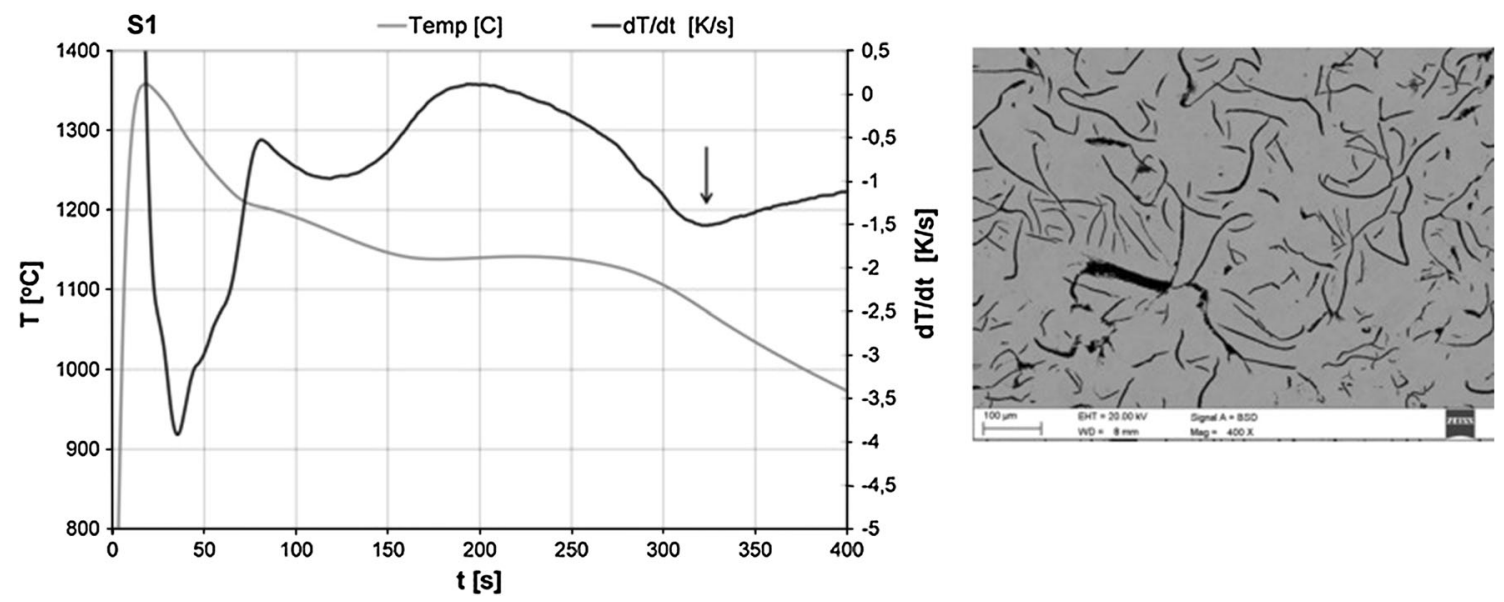

Fig. 9 TDA curves for cast iron prepared with the use of pig iron S1
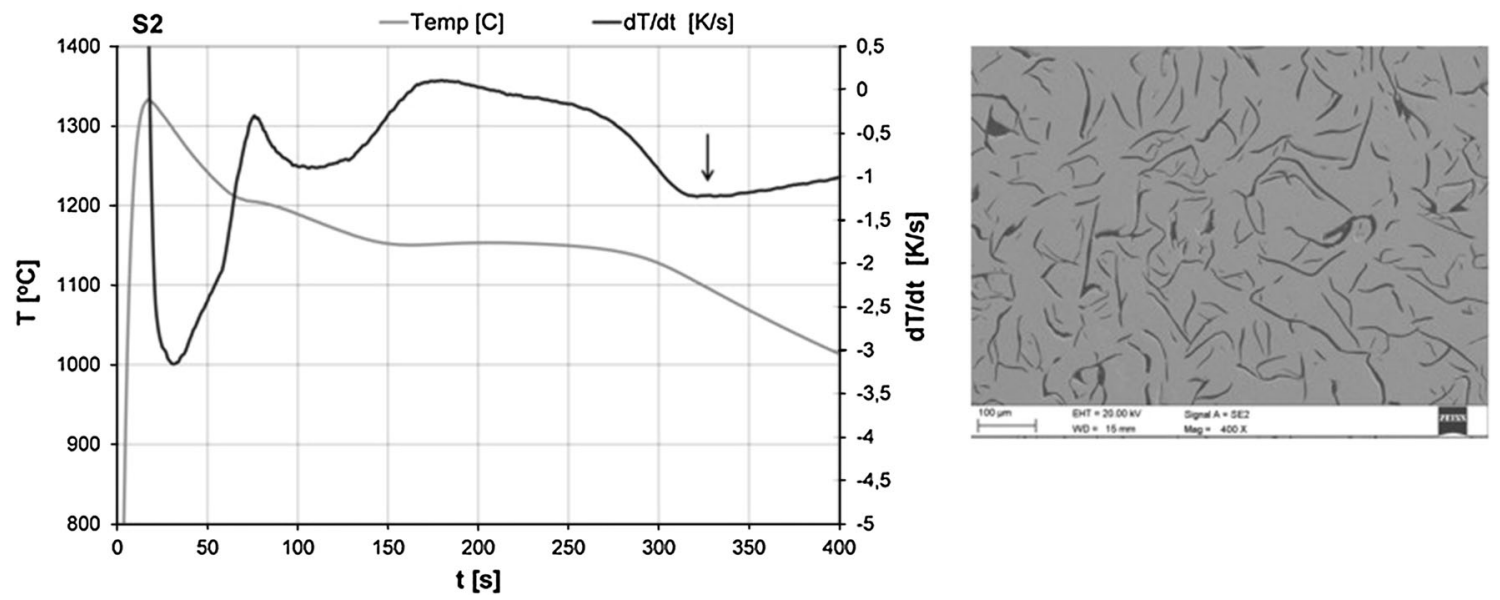

Fig. 10 TDA curves for cast iron prepared with the use of pig iron S2

iron and those produced on the basis of pig iron occurred without undercooling, thus it was impossible to describe the carburizer influence on the nucleation process during the $\mathrm{L} \rightarrow \gamma$ or $\mathrm{L} \rightarrow \gamma+\mathrm{Cgr}$ transformations.
In the case of cast iron prepared with the use of petroleum coke, anthracite and natural graphite, the crystallization curves revealed additional thermal effects in the range of 1070$1123{ }^{\circ} \mathrm{C}$. The size and shape of the registered thermal effect is 
characteristic of the type of carburizer used. For synthetic graphite, the effect is small or does not occur. On most of the registered crystallization curves, it can be seen on the righthand side of point $\mathrm{H}$, except for cast iron prepared with petroleum coke KN1, where the effect is placed on the left-hand side of the mentioned point. Such an effect is not observed for cast iron prepared with the use of pig iron (Fig. 9, 10).

In order to explain the thermal effect causes, the chemical elements content was analyzed for the studied alloys. The widest range of changes in the concentration of particular elements was stated for $\mathrm{Cr}, \mathrm{Ni}$, and $\mathrm{Cu}$. The chromium content in the alloys varied from $0.066-0.364 \%$ for scrap steel charge material to $0.018-0.033 \%$ for pig iron. Significant differences were also registered for nickel. Nevertheless, when analyzing the TDA curves for scrap steel and synthetic graphite (GS1, Fig. 4), where the chromium and nickel content were the highest $(0.364 \% \mathrm{Cr}$ and $0.118 \% \mathrm{Ni})$, the effect of $\mathrm{HE}^{\prime} \mathrm{H}^{\prime}$ did not occur. Thus, the effect is probably not caused by the crystallization of carbides (in this case $\mathrm{Cr}_{3} \mathrm{C}$ ), as is explained in the literature (Ref 13).

Another experiment was planned to examine the possible effect of copper on additional thermal effect occurrence. The addition of copper was introduced to cast iron prepared with the use of pig iron with an initial $0.029 \% \mathrm{Cu}$ content, which resulted in a total $0.51 \% \mathrm{Cu}$ content. The $\mathrm{HE}^{\prime} \mathrm{H}^{\prime}$ thermal effect was not observed on TDA curves registered before and after copper addition.

The gas content was analyzed in the studied alloys. The results of oxygen, hydrogen, and nitrogen are presented in Table 3.

The highest nitrogen content was measured for the cast iron recarburized with the petroleum coke and the anthracite and the

Table 3 Hydrogen, oxygen, and nitrogen content in the studied cast irons

\begin{tabular}{lccc}
\hline Melt number & H, ppm & N, ppm & O, ppm \\
\hline A1 & 2.5 & 83 & 91 \\
GN1 & 1.7 & 66 & 35 \\
GS2 & 2.2 & 63 & 39 \\
KN2 & 1.8 & 83 & 37 \\
S2 & 1.8 & 51 & 45 \\
\hline
\end{tabular}

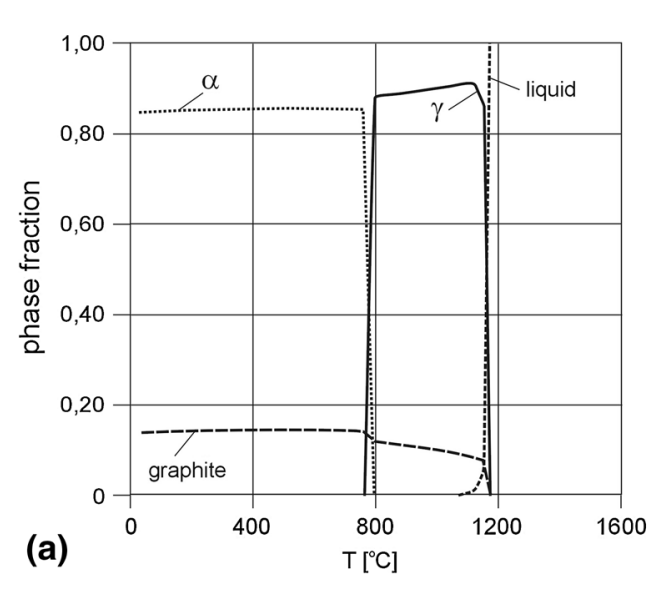

lowest for this produced on the pig iron base. An increase in $\mathrm{N}$ is especially explicit for cast iron prepared with the use of petroleum coke (up to $166 \mathrm{ppm}$ for melts not included in Table 3). The nitrogen content for steel scrap used during the studies was $100 \mathrm{ppm}$ and for pig iron it was $43 \mathrm{ppm}$. The lowest values of nitrogen were registered for melts prepared with pig iron and scrap steel together with synthetic graphite.

The oxygen level is significantly higher for cast iron carburized with the use of anthracite and petroleum coke. Other carburizers give lower oxygen contents in cast iron.

Numerical modeling was performed using ThermoCalc software to determine the theoretical description of the structure components for the studied cast irons (Ref 14). It enables thermodynamic calculations of multicomponent equilibrium systems and phase content in the function of temperature for given chemical compositions of alloy ( $\operatorname{Ref} 15,16)$. Figure 11 is a diagram showing the phase components content for cast iron in the function of temperature.

The calculated phases content enabled a description of alloy crystallization in equilibrium state conditions. The primary crystallization of A1 cast iron starts with austenite crystallization, which is the leading phase. Next, graphite crystallizes from liquid during the eutectic formation. Phases resulting from impurities crystallize in the solid state, during the secondary crystallization, and after the austenite transforms into ferrite (Fig. 11). This results mainly from the decreasing solubility of impurities in the matrix phase. In Fig. 12 and 13, the pseudobinary equilibrium system was presented for alloys KN2 and $\mathrm{S} 1$. Based on these diagrams, additional thermal effects $\left(\mathrm{HE}^{\prime} \mathrm{H}^{\prime}\right)$ can be interpreted. In the case of cast steel prepared with the use of scrap steel and carburizer, under the eutectic transformation line the ternary field appears (austenite + graphite + liquid), whose temperature range grows together with the increasing carbon content. For $\mathrm{KN} 2$ cast iron, the temperature range of the above-mentioned field is $9{ }^{\circ} \mathrm{C}\left(1162-1153{ }^{\circ} \mathrm{C}\right.$, Fig. 12). A change in the graphite precipitation is also seen in the diagram representing the phase content in the function of temperature. For cast iron prepared with the use of pig iron, the temperature range of the ternary field is only $1{ }^{\circ} \mathrm{C}$ (Fig. 13), and thus the thermal effects are not registered during the TDA measurement. Additionally, during the measurement the conditions of cooling differ from the equilibrium state. The thermal effect position on the TDA curves may be affected by the type of carburizer used, which determines the carbon absorption kinetics. Due to

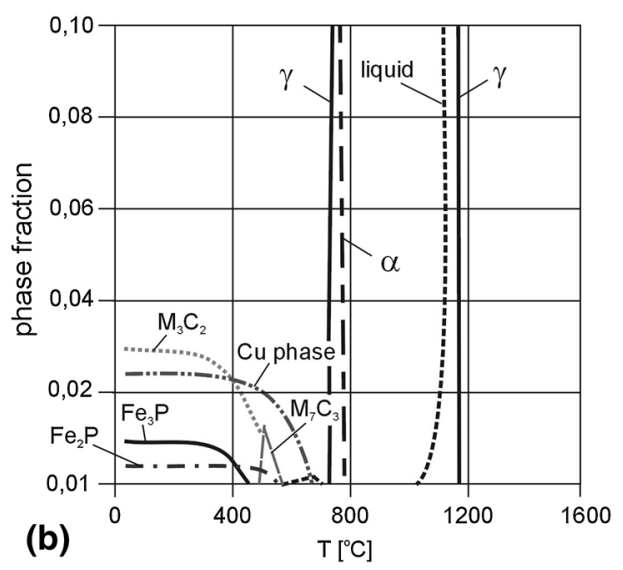

Fig. 11 Phase content in the function of temperature for cast iron A1-19S (a magnified fragment of the diagram is on the right) 

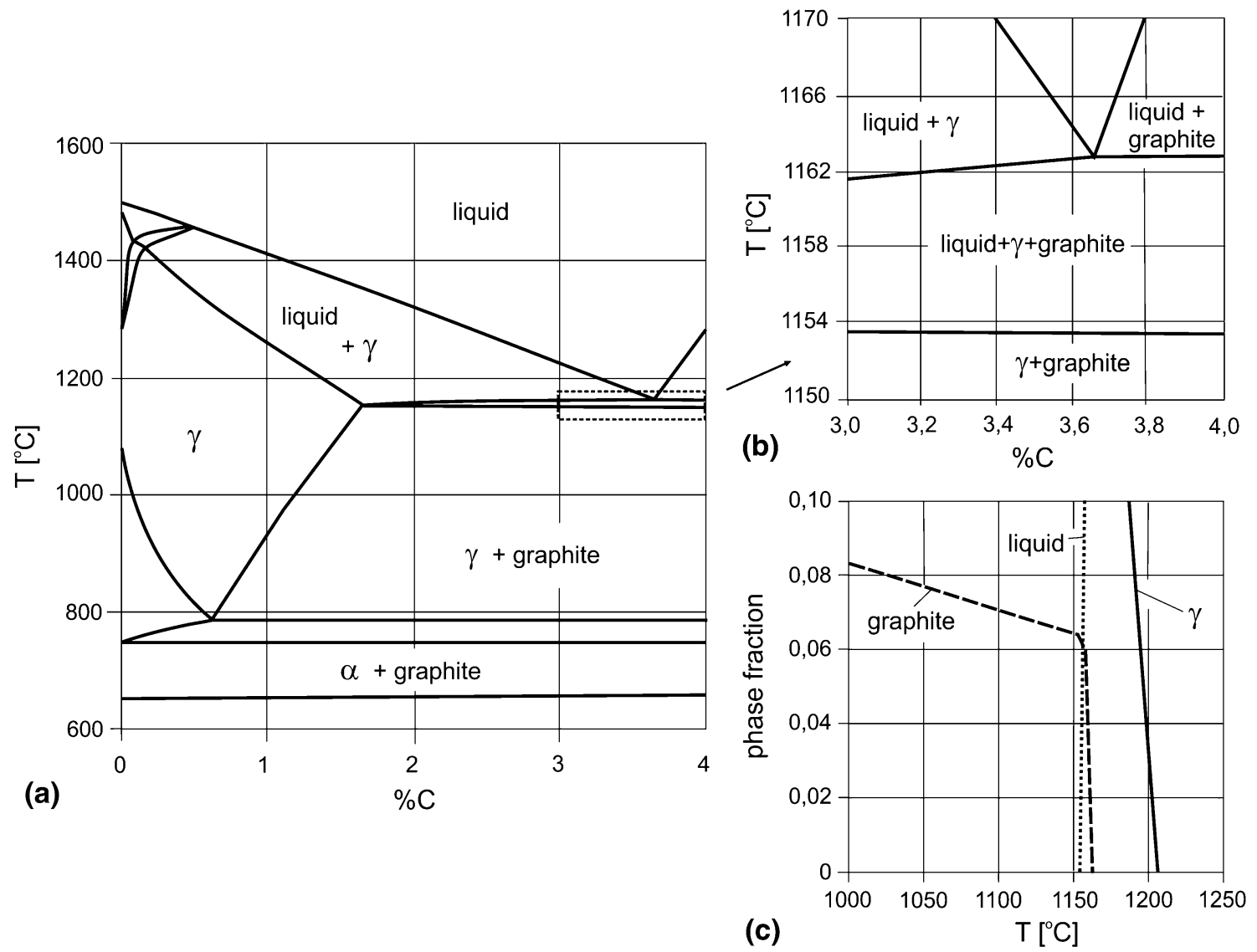

Fig. 12 Pseudo-binary equilibrium system for a carbon content in the range of $0-4$ wt.\%, including the chemical composition of KN2 cast iron (scrap steel + petroleum coke) together with a magnified fragment showing the ternary field and diagram of the phase content in the function of temperature (on the right)

similarities of the obtained diagrams, only three of the studied cast irons were presented.

\section{Summary}

Based on the conducted studies, additional thermal effects occurring in the final stage of primary crystallization can be explained by the following hypotheses:

Thermal effect $\left(\mathrm{HE}^{\prime} \mathrm{H}^{\prime}\right)$ is an effect of secondary thermal flux connected with moving the heat center of the specimen casting. The temperature measuring point is initially equivalent with the heat center of the casting, but in the final stage of solidification it is outside the heat center, thus registering the end of solidification twice, i.e., first in the point where initially it was the heat center and the second time due to a secondary thermal flux from the real heat center final position (for solidus temperature). The type of carburizer may influence the phenomenon, considering the diverse kinetics of graphite precipitation (which manifests itself by, for example, eutectic crystallization at different undercooling).

Additional thermal effects can occur due to the crystallization of low-point eutectics, as an effect of segregation and changing solubility of impurities and carbon in austenite in the final stage of solidification. The influence of carburizer type may influence the process due to different impurities content and diverse kinetics of graphite precipitation.
The thermal effects result from crystallization of graphite whose thermal effect has shifted toward the lower temperature. Part of the TDA diagrams revealed that eutectic crystallization takes place at higher undercooling. At the final stage of solidification, the kinetics of graphite precipitation can be intensified by a higher carbon content in the liquid metal (i.e., non-equilibrium carbon enrichment of liquid-saturated liquid) and by decreasing the solubility of carbon in austenite, thus resulting in an additional thermal effect on the TDA curves.

The carburizers' influence on undercooling during the eutectic crystallization process is clear. The lowest undercooling rate was recorded for the melt with pig iron, then for synthetic graphite, natural graphite, anthracite, and petroleum coke (the highest undercooling rate). So a hypothesis can be formulated that eutectic cells are created most effectively with the presence of carbon from pig iron (the highest nucleation potential), and then for the graphite materials (crystallographic similarity with the carbon precipitation in the cast iron). The most difficult eutectic crystallization is for anthracite and petroleum coke (higher undercooling is necessary); whereas the large undercooling that is present before the eutectic crystallization starts influences the crystallization kinetics - the crystallization time becomes shorter and the thermal effect is more visible (a steeper peak for $\mathrm{KN}, \mathrm{A}$, and $\mathrm{SiC}$ than for the $\mathrm{GS}, \mathrm{GN}$, and $\mathrm{S}$ carburizer grade). This problem is now being examined by the authors, and after a positive solution is reached it will be published in another paper. 

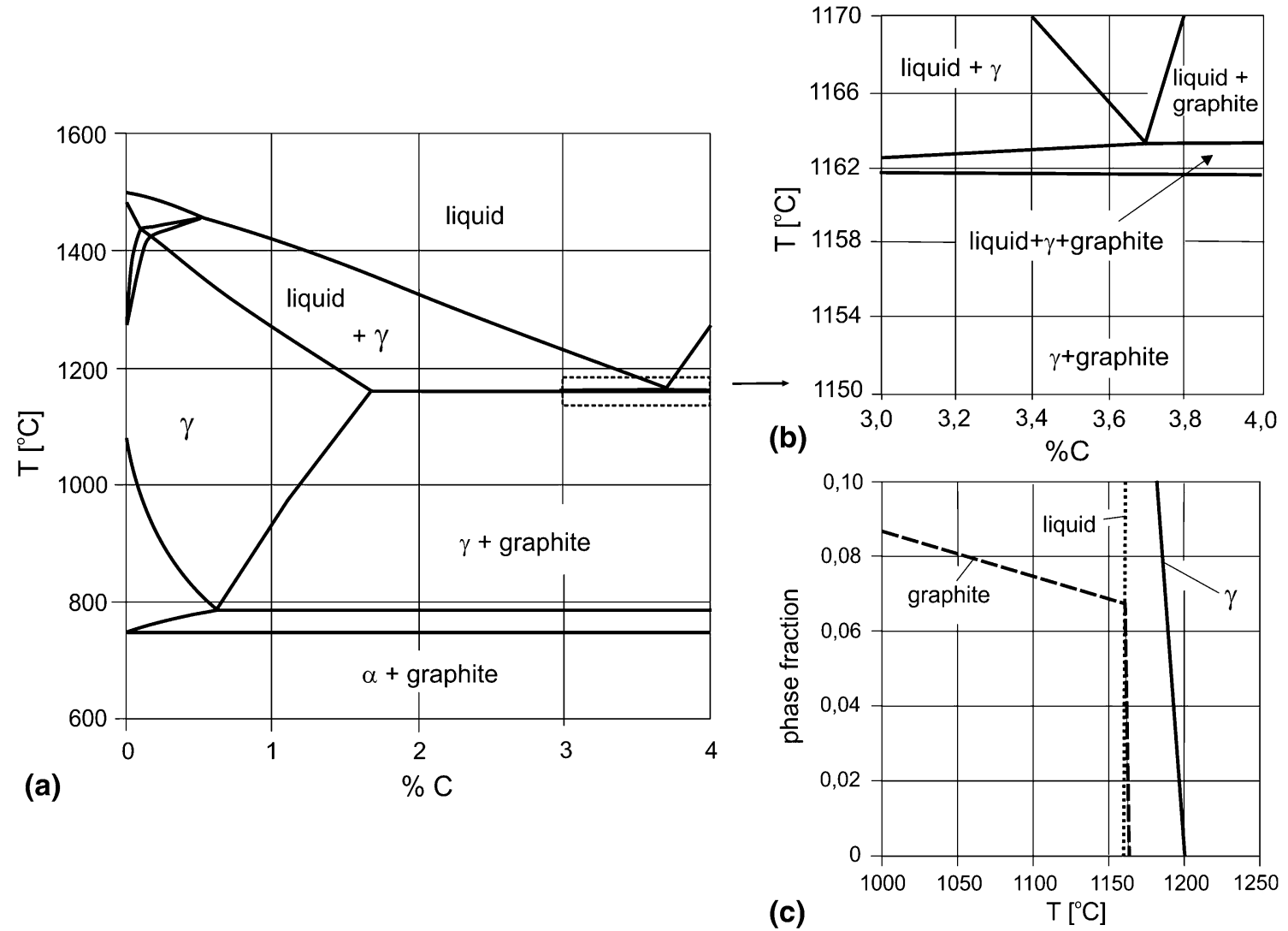

Fig. 13 Pseudo-binary equilibrium system for carbon content in the range of 0-4 wt.\%, including the chemical composition of S1 cast iron (pig iron) together with a magnified fragment showing the ternary field and diagram of the phase content in the function of temperature (on the right)

The observed differences in the solidification path can also result from the structure of carburizers, which is different from graphite (in the case of petroleum coke and anthracite). At incomplete solution of carburizer in the liquid metal, the nuclei can cause carbon precipitant growth with a structure that is similar (fully or partially) to the structure of petroleum coke or anthracite.

\section{Open Access}

This article is distributed under the terms of the Creative Commons Attribution License which permits any use, distribution, and reproduction in any medium, provided the original author(s) and the source are credited.

\section{References}

1. D. Bartocha, K. Janerka, and J. Suchoń, Charge Materials and Technology of Melt and Structure of gray Cast Iron, J. Mater. Process. Technol., 2005, 162-163, p 465-470

2. M. Gagné, The Sorelmetal Book of Ductile Iron, A New Rio Tinto Publication to Support the Ductile Iron Industry, Warsaw, 2006

3. K. Janerka, J. Jezierski, D. Bartocha, and J. Szajnar, Heredity of the Structure and Properties of Grey Cast Iron Melted on a Basis of Steel Scrap, Adv. Mater. Res., 2013, 622-623, p 685-689

4. K. Janerka, M. Pawlyta, J. Jezierski, J. Szajnar, and D. Bartocha, Carburizers Properties Transfer into a Structure of Melted Cast Iron, J. Mater. Process. Technol., 2014, 214, p 794-801

5. K. Janerka, D. Bartocha, J. Szajnar, and J. Jezierski, The Carburizer Influence on the Crystallization Process and the Microstructure of Synthetic Cast Iron, Arch. Metall. Mater., 2010, 55, p 851-859
6. K. Janerka, D. Bartocha, J. Jezierski, and J. Szajnar, The Effect of the Carburiser Quality on the Cast Iron Recarburization Process, Foundry Trade J. Int., 2010, 184, p 282-286

7. K. Janerka, D. Bartocha, J. Szajnar, and M. Cholewa, The Influence of Different Kind of Carburizers and Carburization on the Effectiveness and Iron Structure, Arch. Metall. Mater, 2007, 52, p 467-474

8. K. Janerka, J. Jezierski, and J. Szajnar, The Evaluation of Effectiveness of Liquid Cast Iron Recarburization Process by Using Different Carburizers and Methods of Recarburization, 20th Anniversary International Conference on Metallurgy and Materials METAL, METAL 2011, p 156-162

9. S. Jura et al., Odlewnictwo. Topienie stopów odlewniczych I, ich diagnostyka, Wyd. Pol. Śląskiej, Gliwice, 1993 (in Polish)

10. S. Pietrowski and B. Pisarek, Computer-Aided Technology of Melting High-Quality Metal Alloys, Arch. Metall. Mater, 2007, 52, p 481-486

11. M. Stawarz, Kompleksowa ocena jakości żeliwa sferoidalnego, Eksploatacja i Niezawodność, 2004, 2, p 55-58 (in Polish)

12. A. Studnicki, Wspomagana komputerowo ocena jakości żeliwa, Wybrane procesy odlewnicze, M. Cholewa, Ed., Wyd Pol Ślaskiej, Gliwice, 2008 (in Polish)

13. S. Pietrowski, B. Pisarek, R. Władysiak, G. Gumienny, and T. Szymczak, TDA Curves of Metals Alloys and the Control of Their Quality, Advances in Theory and Practice Foundry, J. Szajnar, Ed., PAN, Katowice, 2009

14. Foundation of Computational of Thermodynamics, Thermo-Calc Software, User Guide v. S, Foundation of Computational of Thermodynamics, Sweden, 1995-2008

15. M. Kondracki and M. Cholewa, Studies of Transition Zone Phenomena for AlSi Matrix Composite Reinforced with Intermetallic Phases, 21st International Conference on Metallurgy and Materials, METAL, Brno, Czech Republic, 2012, p 1135-1141

16. A. Studnicki, M. Kondracki, J. Szajnar, and T. Wróbel, Crystallization of Low-Alloyed Construction Cast Steel Modified with V and Ti, Arch. Foundry Eng., 2013, 13, p 92-96 